\title{
Bringing Dynamism and Engagement in Classroom Through WhatsApp
}

\author{
Richa Mishra ${ }^{1}$, Kartikeya $\mathbf{M}^{2}$ \\ ${ }^{1}$ Mathmateics and Humanities, Institute of Technology, Nirma University, Ahmedabad. \\ ${ }^{2}$ Eletctrical Engineering, Pandit Deendayal University, Gandhinagar, Gujarat \\ ${ }^{1}$ richa.mishra@nirmauni.ac.in
}

\begin{abstract}
Digital natives in our classrooms have different orientation and learning mind-set. The information they need is to be accessible instantly and all the time. Sometimes engaging tools can add more interest and excitement in the whole learning experience. The students' sample of this research work were connected and disseminated through very dynamic tool: Whatsapp. The cross-messaging platform was easily accessible and could be used for diverse kinds of files/links/documents sharing, which benefitted all. This app brings dynamism and more engagement between teacher-student since it is a very familiar tool and has ease of use.
\end{abstract}

Keywords: engagement, teaching, technology, whatsapp, dynamic, ease of use.

\section{Introduction}

Higher education institutions everywhere has various challenges related with academics, research and other domains but one of the basic challenges is happening in the classroom, and that is lack of engagement between teachers and students [1]. The

\section{Richa Mishra}

Mathmateics and Humanities,

Institute of Technology, Nirma University, Ahmedabad.

richa.mishra@nirmauni.ac.in diversity and heterogeneous students [2](fast and slow learners) adds to this concern. We are still in the learning trajectory of how to engage the students and how to make learning interesting. The second concern is to develop lifelong learning. The challenges of 21 st century is taking toll on everything, traditional education system is on the verge of collapse and new and reformed system is yet not in the place. The uncertain conditions and works places are demanding learning to be experiential and student centric. That means shifting the paradigm from Teaching to Learning.

Teaching-learning and attainment of learning is evolving. It is changing its shapes and forms. Now classroom interactions, dissertations, discussions, reflective learning $\log s$, entries, assignments submissions, viva-voce et al are part of assessment tools. Along with this traditional teaching method with chalk and talk are now impasse, they don't have enough dynamism to suit the need of heterogeneous students. The students in classrooms are Digital native sand like to do things in their own space, pace and time and also demand $24 \times 7$ accesses to the content and mentors [3].

One of the attribute of these digital natives are that they are organic readers and searchers. They don't mind sifting through the information at ease (they have search tools) and find old traditional methods of engagements boring and uninspired. 


\subsection{Understanding WhatsApp}

WhatsApp is a Smartphone application that that has replaced SMS platform. It is compatible with all types of devices and operating systems. Apart from sending and receiving messages to and from individuals or groups, WhatsApp has become very popular [4] due to its easy to operate and diverse tasks, for examples chatting, texting, , sending images/ audio files/video files, and sharing the links etc. The latest messaging app usage statistics show that WhatsApp have 1.6 billion users worldwide [5] 97\% of all smartphone users in India use mobile Apps for daily communication. For $96 \%$ of them [6], WhatsApp is the first choice for chatting platform.

India has approximately 200 million active users on WhatsApp in 2017. Right now, there is an estimated 250-300 million users in India. It is also popular because it has enormous reach, globally [7] Since mobile devices are so convenient to use and users can carry them at all time, they omnipresent in our life. Empirical research shows that $77 \%$ of all Indian internet users actually use digital platform to do their tasks.

Statista's analysis [8] from 2018 shows that WhatsApp has surpassed Facebook, G-mail, Facebook Messenger, Instagram, and more. It has $91.7 \%$ reach for social media application users in India [8].

\section{Preamble}

Digital communication is now a very common form of communication form between students and teachers. With emails as legitimate documents, ecirculars /notices etc. are now circulated through emails. Other popular tools are, SMS, Facebook groups, Twitter, and recently WhatsApp. All these tools have their own different characteristics and ease of use. Teachers around the world are trying to integrate these tools in their teaching and learning processes.

\section{Related Work}

Previous studies have compared different Instant Messaging (IM) services. A study done on high school students showed academic support after hours to the students, It has shown how personal connection is much more fruitful than the impersonal connection like emails. The personal connection helps teacher to reach out to the student in more rrelevant and individually tailored manners [9] [10]. Various studies are conducted to show the effectiveness of different platforms of Instant Messaging (IM) between faculty and class. They show that IMs can enhance learning potential [11]; it also makes learners more active; informal rapport building between students [12]; augmentation of familiarity between students and faculty going beyond course content and personal issues [13]; sense of belonging and community [14], thin teacher-student social barriers [15]; though few teachers were not very comfortable with the idea [16]; others pointed out that this creates a negative impact in terms of them using incorrect language and grammar [17].

Facebook-Groups in classrooms are used by many teachers as a learning and information dissemination tool., it also promotes iinteraction between students and teachers but privacy is one of the issue [18], A Meta research of more than 20 papers [19] on twitter as the platform has reported that it has potential for collaborative learning, asynchronous learning and learning at your pace but on the other hand it is not an easy platform to use and the character length is a great constrain in smooth interaction,

Table 1: Comparative study of various platforms as learning tool

\begin{tabular}{|l|l|l|l|l|l|l|}
\hline Attributes & $\begin{array}{l}\text { Google- } \\
\text { website }\end{array}$ & $\begin{array}{l}\text { Faceboo } \\
\text { k Group }\end{array}$ & SMS & $\begin{array}{l}\text { WhatsAp } \\
\mathbf{p}\end{array}$ & $\begin{array}{l}\text { Blog on } \\
\text { WordPres } \\
\text { s }\end{array}$ & Emails \\
\hline Cost & Free & Free & Cost & Free & Free/Cost & Free \\
\hline Accessibility & $\begin{array}{l}\text { Through } \\
\text { official } \\
\text { mail } \\
\text { account }\end{array}$ & $\begin{array}{l}\text { Through } \\
\text { Facebook } \\
\text { Account }\end{array}$ & Direct & Direct & $\begin{array}{l}\text { Through } \\
\text { WordPress } \\
\text { Account }\end{array}$ & $\begin{array}{l}\text { Throug } \\
\text { h Email } \\
\text { Account }\end{array}$ \\
\hline Ownership & No & No & No & Yes & NO & No \\
\hline $\begin{array}{l}\text { Ease of having a } \\
\text { Group }\end{array}$ & Not easy & Yes & No & Yes & No & Yes \\
\hline Interaction & $\begin{array}{l}\text { Not } \\
\text { Smooth }\end{array}$ & Yes & No & Yes & $\begin{array}{l}\text { Not } \\
\text { Smooth }\end{array}$ & $\begin{array}{l}\text { Not } \\
\text { Smooth }\end{array}$ \\
\hline Engagement & Not high & Medium & No & Very High & No & $\begin{array}{l}\text { Not } \\
\text { very } \\
\text { high }\end{array}$ \\
\hline $\begin{array}{l}\text { Sharing of Audio } \\
\text { and Videos }\end{array}$ & Easy & Easy & $\begin{array}{l}\text { Not } \\
\text { Easy }\end{array}$ & $\begin{array}{l}\text { Very easy } \\
\text { and fast }\end{array}$ & Not easy & $\begin{array}{l}\text { Links } \\
\text { can } \\
\text { shared }\end{array}$ \\
\hline $\begin{array}{l}\text { Instant Message } \\
\text { transfer }\end{array}$ & No & Yes & Yes & Yes & Yes & Res \\
\hline Read receipts and & No & No & NO & Yes & No & Maybe \\
\hline $\begin{array}{l}\text { Retrieval } \\
\text { categorisation of } \\
\text { document/media/link } \\
\text { s }\end{array}$ & easy & Not easy & $\begin{array}{l}\text { Not } \\
\text { easy }\end{array}$ & Easy & $\begin{array}{l}\text { Can be } \\
\text { easy }\end{array}$ & $\begin{array}{l}\text { Not } \\
\text { easy }\end{array}$ \\
\hline $\begin{array}{l}\text { Ease of search } \\
\text { operation }\end{array}$ & Easy & Not easy & $\begin{array}{l}\text { Not } \\
\text { easy }\end{array}$ & Easy & Not easy & $\begin{array}{l}\text { Can be } \\
\text { easy }\end{array}$ \\
\hline
\end{tabular}

Based on these studies, author has made a comparison table of the most common social media and instant messaging tools in education

The hhigh infiltration of affordable Smartphones into the market and cheap data charges has empowered majority of the students and this in turn 
has spurred the growth of WhatsApp as a communication platform for various student groups, and more recently it is seen that few teachers are also in the group. Though, this group basically is not very structured.

\section{Intervention}

Applied literature is one of the courses offered as the elective course ton one of the premier university of western region of India. The engineering students were offered Institute Electives. Applied Literature comprises contemporary poems/literary pieces/ excerpts / movies are one of the most popular course. This is chosen by 66 students. The students belonged to branches: Computer science; Information Technology; Instrumentation and Control, and Civil Engineering.

The group was very eclectic and it was decided by the author to make a WhatsApp group for ease of information dissemination. The group was created by a student and was sent invitation link organically. The author was also one of the members. The syllabus of the course was shared through pdf file.

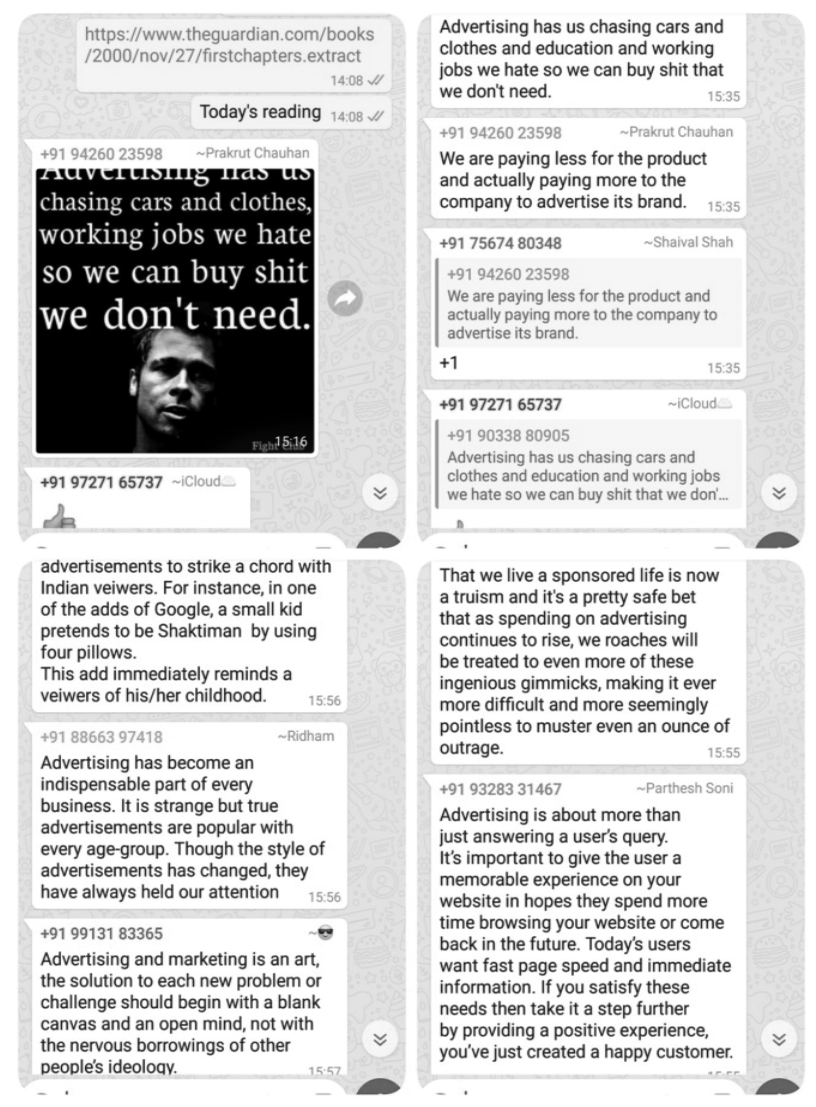

Fig:1Collated screenshots of one of the activity
Before every class author used to send the link of the reading during the classes, if the need to have any related reading was felt it was shared through googling and WA. This created very engaging and dynamic flow in the class.

Author-teacher also used active learning tools like one-minute paper after discussion ( fig 1.) (fig:1Collated screenshots of one of the activty)

\section{Results}

After the course completion a survey was taken by the students related to use of WhatsApp instead of traditional emails/ google website. And few of the

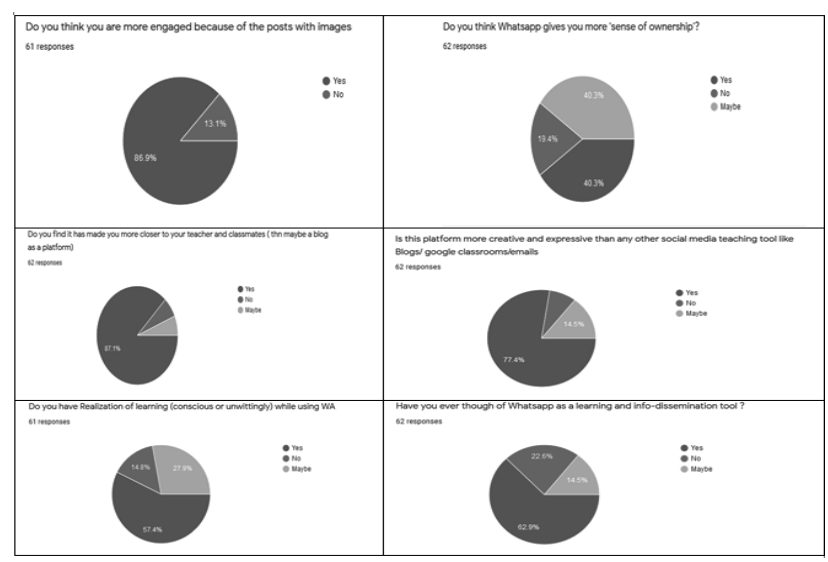

Fig 2: Collated Result

results are Though, students were very much at ease in using the application. They pointed out disadvantages too. Most of them pointed out Waste of time, "Eats up a lot of time. Especially when we're waiting for reply on a group or even personal chat", someone also pointed out how it distract people. Someone mentioned about the 'addictiveness' of the app thus leading to 'random things'. Technical issues like 'If WhatsApp is uninstalled without backup all messages and important chats will be gone" and "1) privacy, since the numbers are shared 2) unmoderated" was also mentioned. Students also pointed out informal language and posts due to the very nature of the platform.

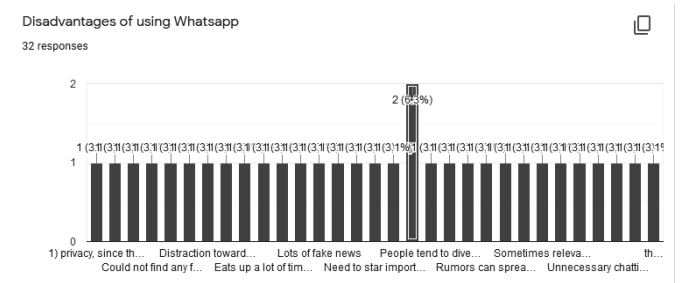

Fig 3: Result of the survey about disadvantages of WhatsApp 


\section{Concluding remarks}

WhatsApp is comparatively a new phenomenon to be used as a learning tool in classrooms little or no research exists regarding its influence on interpersonal communication in general, and between college teachers and their students in particular. Since literature is a subject where plethora of information is present in World Wide Web, this medium added dynamism, enrichment and more value. It is a fact that WhatsApp has become a shared and valued platform that enriched accessibility, collaboration, and spurred motivation to take an active part in academic assignments and classroom teaching .

Although the author has used this tool only for a semester of months, the findings of this research revealed an extraordinary tool that has educational and academic potential.

\section{Future Scope}

As this phenomenon is relatively new and its usage as formal teaching-learning tool has not yet been used, it will be interesting to conduct an exploratory research.

\section{Reference}

[1] Cooper, J. L. \& Robinson, P. (2000). The arguments for making large classes seem small. New Directions for Teaching and Learning, 2000(81), 5-16. [verified 1 Mar 2008] h t t p : / / w w w. c s u p o mo na.ed u / $\sim$ dolce/pdf/cooper.pdf

[2] MosheTatarGabrielHorenczyk, The Hebrew University of Jerusalem, School of Education, Mt. Scopus, Jerusalem 91905, Israel https://doi.org/10.1016/S0742-051X(03)000246

[3] https://content.taylorfrancis.com/books/ download? dac $=$ C2010-0-36513-1\&isbn $=$ $9781136879913 \&$ format $=$ googlePreviewPdf

[4] Karen Church, Rodrigo de Oliveira, What's up with whatsapp?: comparing mobile instant messaging behaviors with traditional SMS, MobileHCI '13 Proceedings of the 15th international conference on Human-computer interaction with mobile devices and services Pages 352-361
[5] https://www.messengerpeople.com/globalmessenger-usage-statistics/

[6] https://www.messengerpeople.com/globalmessenger-usage-statistics/

[7] https://www.messengerpeople.com/messagingapps-in-india/

[8] https://www.similarweb.com/blog/mobilemessaging-app-map-2018

[9] Hrastinski, S., Edman, A., Andersson, F., Kawnine, T., \& Soames, C. A. (2014). Informal math coaching by instant messaging: Two case studies of how university students coach K-12 students. Interactive Learning Environments, 22(1), 84-96.

[10]R Mishra, K Kotecha, Formative Assessment through Computer Mediation: Enriching Student Engagement. Journal of Engineering Education Transformations, [S.1.], p. 87-92, jan. 2015.

[11]Mishra, Kotecha Teaching Communication Skills Student Engagement Through BloggingInternational Journal of Humanities and Social Science ( International Journal of Humanities and Social Sciences ( IJHSS ) (Vol.2, No. 2),2012

[12]Smit, I. (2012). WhatsApp with BlackBerry; Can Messengers (BBM) be MXit?. In Proceedings of the 14th Annual Conference on World Wide Web Applications. Cape Peninsula University of Technology, Cape Town, South Africa.

[13]Smit, I. (2012). WhatsApp with BlackBerry; Can Messengers (BBM) be MXit?. In Proceedings of the 14th Annual Conference on World Wide Web Applications. Cape Peninsula University of Technology, Cape Town, South Africa.

[14]Cifuentes, O. E., \& Lents, N. H. (2011). Increasing student-teacher interactions at an urban commuter cam-pus through instant messaging and online office hours. Electronic Journal of Science Education, 14(1Doering, Cynthia Lewis, G. Veletsianos, K. Nichols-Besel, Preservice teachers perceptions of instant messaging in two educational contexts, Journal of Computing in Teacher Education 
[15]Doering et al., 2008, Using the Technological, Pedagogical, and Content Knowledge Framework to Design Online Learning Environments and Professional Development,https://doi.org/10.2190/EC.41.3.d

[16]Doering et al., 2008, Using the Technological, Pedagogical, and Content Knowledge Framework to Design Online Learning Environments and Professional Development,https://doi.org/10.2190/EC.41.3.d

[17]Richard T. Sweene, yPage 1of 10Millennial B e haviors \& D e mographics, http://unbtls.ca/teachingtips/pdfs/sew/Millennial -Behaviors.pdf
[18]Wang, Woo, \& Quek; Using the Facebook group as a learning management system: An exploratory study, British Journal of Educational Studies, doi 10.1111/j.1467-8535.2011.01195.x

[19]Wang, Woo, \& Quek; Using the Facebook group as a learning management system: An exploratory study, British Journal of Educational Studies, doi 10.1111/j.1467-8535.2011.01195.x

[20]R Mishra, K Kotecha, Are we there yet! Inclusion of higher order thinking skills (HOTs) in assessment, Journal of Engineering Education Transformations, Jan 2016, 